Rev. Bras. Saúde Prod. Anim., Salvador, v.14, n.3, p.437-447 jul./set., 2013 http://www.rbspa.ufba.br ISSN 15199940

\title{
Avaliação de fenos de capim-buffel colhido em diferentes alturas de corte
}

\author{
Evaluation of buffelgrass hay harvested at different cutting heights
}

\author{
PINHO, Ricardo Martins Araujo ${ }^{1 *}$; SANTOS, Edson Mauro ${ }^{1}$; BEZERRA, Higor Fábio \\ Carvalho ${ }^{1}$; OLIVEIRA, Juliana Silva de ${ }^{1}$; CARVALHO, Gleidson Giordano Pinto de ${ }^{2}$; \\ CAMPOS, Fleming Sena ${ }^{3}$; PEREIRA, Gildenia Araujo ${ }^{1}$; CORREIA, Robervânia \\ Maria $^{1}$
}

\footnotetext{
${ }^{1}$ Universidade Federal da Paraíba, Centro de Ciências Agrárias, Departamento de Zootecnia, Areia, Paraíba, Brasil.

${ }^{2}$ Universidade Federal da Bahia, Escola de Medicina Veterinária e Zootecnia, Departamento de Zootecnia, Salvador, Bahia, Brasil.

${ }^{3}$ Universidade Federal da Bahia, Escola de Medicina Veterinária e Zootecnia, Programa de PósGraduação em Zootecnia, Salvador, Bahia, Brasil.

*Endereço para correspondência: ricardo-zootec@hotmail.com
}

\section{RESUMO}

Objetivou-se avaliar o rendimento forrageiro, composição bromatológica e recuperação de matéria seca do feno de capim-buffel (Cenchrus ciliaris L.), colhido em diferentes alturas de corte. O experimento foi realizado na Estação Experimental Pendência, da Empresa Estadual de Pesquisa Agropecuária da Paraíba S.A. (EMEPA), situada no Município de SoledadePB. Utilizou-se um delineamento experimental em blocos casualizados, com quatro alturas de corte $(30 ; 40 ; 50$ e $60 \mathrm{~cm})$ e cinco repetições. O rendimento forrageiro foi influenciado pela altura de colheita, com aumento linear alcançando produção de matéria seca de $7206,78 \mathrm{~kg} /$ ha a $60 \mathrm{~cm}$ de altura. Observou-se efeito de altura de colheita para os conteúdos de lâmina, colmo e relação lâmina:colmo na matéria seca, em que os valores da relação lâmina:colmo diminuíram com o aumento da altura de colheita, obtendo valores de $0,87 \mathrm{e}$ 0,48 quando colhidos aos 30 e $60 \mathrm{~cm}$ de altura, respectivamente. Obteve-se efeito quadrático de altura de colheita apenas para o teor de fibra em detergente neutro, com teores variando de 71,82 a $77,08 \%$ na matéria seca. Os valores médios de matéria seca do feno variaram entre 82,44 e $84,48 \%$. A recuperação de matéria seca durante a desidratação diminuiu em função das alturas de colheita, apresentando comportamento linear com menor média observada no capim colhido a $60 \mathrm{~cm}$ de altura (76,58\%). A ausência de variação nos constituintes bromatológicos e nas perdas de matéria seca final e as maiores produções de biomassa nas maiores alturas de colheita permite concluir que o capim-buffel seja colhido nas alturas de colheita que possibilite maior produção.

Palavras-chave: Cenchrus ciliaris, produção de matéria seca, qualidade, semiárido

\section{SUMMARY}

This study aimed to evaluate the forage yield, chemical composition and dry matter recovery of buffel grass hay (Cenchrus ciliaris L.), at different cutting heights. The experiment was conducted at the Estação Experimental Pendência of Empresa Estadual de Pesquisa Agropecuária da Paraíba S.A (EMEPA), located in city of Soledade-PB. A randomized complete block design was used, with four cutting heights (30; 40; 50 and $60 \mathrm{~cm})$ with five replicates. The forage yield had effect with a linear increase in values achieving dry matter yield $7206.78 \mathrm{~kg} / \mathrm{ha}$ for $60 \mathrm{~cm}$ height. There was harvesting height effect for leaf, stem and leaf:stem ratio in dry matter, wherein the values of leaf:stem ratio decreased with increasing harvesting height, getting values of 0.87 to 0.48 when harvested at 30 and $60 \mathrm{~cm}$ height, respectively. Quadratic effect was observed in harvesting height only to the neutral detergent fiber, with contents 
ranging from 71.82 to $77.08 \%$ in dry matter. The average values of dry matter of hay were between 82.44 and $84.48 \%$. The dry matter recovery in dehydration decreased in function of harvesting heights, showing linear behavior, with the smallest average observed for the grass to $60 \mathrm{~cm}(76.58 \%)$. The absence of variation in the bromatological constituents and dry matter final losses and higher biomass production in the highest cutting harvest may conclude that buffel grass is to be harvested in the cutting height that enable greater production.

Keywords: Cenchrus ciliaris, dry matter production, quality, semiarid

\section{INTRODUÇÃO}

A região semiárida é caracterizada, por apresentar uma baixa produtividade nos rebanhos de ruminantes, em função de vários fatores, podendo-se citar $\mathrm{o}$ sistema de manejo extensivo e a forte dependência das disponibilidades quantitativas e qualitativas das pastagens nativas como os mais importantes. Dentro desse contexto, é importante a implantação de um programa de conservação de forragem, seja esta na forma de silagem ou de feno. $\mathrm{O}$ processo de fenação vem sendo utilizado nas diversas regiões do país e ocupa papel importante no manejo das pastagens, por constituir uma alternativa para o problema da estacionalidade de forragens e permitir o melhor aproveitamento do excedente de forragem (AGUIAR et al., 2006).

O capim-buffel (Cenchrus ciliaris) é uma gramínea promissora para as regiões semiáridas do Brasil, devido as suas características de adaptação a essa região. Segundo Medeiros \& Dubeux Junior (2008), esse capim apresenta maior resistência ao déficit hídrico entre as gramíneas cultivadas nas regiões secas devido à sua eficiência no uso da água das chuvas, em função de adaptações morfofisiológicas, que permitem um crescimento rápido no início do período chuvoso, após sofrer déficit hídrico intenso e prolongado. Uma outra característica dessa espécie está relacionada a sua perenidade e ao tipo de crescimento vertical, com altura variando de 0,6 a 1,5m, dependendo da variedade ou cultivar (DANTAS NETO et al., 2000). Além de adaptado às regiões de clima Semiárido, o capimbuffel apresenta atributos favoráveis para ser conservado na forma de feno, por sua alta relação folha: colmo, caules finos e cutícula estreita (EDVAN et al., 2011).

Com relação ao processo de fenação, é importante considerar o momento ideal para o corte da planta, tendo em vista a dificuldade de se associar o conteúdo ideal de matéria seca (MS) com a composição química que assegure um elevado valor nutritivo, sendo com isto importante quantificar essas perdas, com o intuito de identificar o melhor momento de colheita para fenação.

A falta de informações pertinentes do valor nutritivo do capim-buffel e principalmente de suas formas conservadas, como fenos e silagens, vem sendo um obstáculo para o melhor planejamento da escolha de como manejar essa gramínea.

Neste contexto objetivou-se avaliar a produtividade, a composição bromatológica e a recuperação de matéria seca do feno de capim-buffel colhido em diferentes alturas.

\section{MATERIAL E MÉTODOS}

O experimento foi desenvolvido na Estação Experimental Pendência, da Empresa Estadual de Pesquisa Agropecuária da Paraíba S.A - EMEPA, situada na mesorregião do Agreste paraibano, microrregião do Curimataú, 
município de Soledade, nas coordenadas de $7^{\circ} 8^{\prime} 18^{\prime \prime}$ e $36^{\circ} 27^{\prime} 2$ 'W.Gr., com altitude de $534 \mathrm{~m}$. Baseado na classificação de Köppen, o tipo climático da região é Bsh, umidade relativa do ar em torno de $68 \%$, ocorrendo precipitação média de $400 \mathrm{~mm}$ anuais, com déficit hídrico durante quase todo ano.

Foi utilizado um pasto de capim-buffel (Cenchrus ciliaris), já implantado há 28 anos, em uma área cujo solo foi classificado como Luvissolo, com textura média e baixo teor de matéria orgânica.

$\mathrm{O}$ solo apresentou os seguintes atributos químicos (0 -20cm de profundidade): $\mathrm{pH}$ em água $=6,7$; Fósforo $=27,1$, Potássio $=$ $142\left(\mathrm{mg} / \mathrm{dm}^{3}\right)$; Cálcio trocável $=5,45$, Magnésio trocável $=1,1$, Soma de bases $=7,26, \quad \mathrm{H}^{+}+\mathrm{Al}^{+3}=1,49, \quad$ CTC $=$ $8,75\left(\mathrm{cmol}_{d} / \mathrm{dm}^{3}\right)$; Alumínio trocável = 0,0 ; Saturação por bases $=82,97 \%$.

Foi realizada uma adubação no dia 2 de março de 2011, início do experimento, momento em que o pasto foi cortado na altura de $10 \mathrm{~cm}$ do solo para uniformização, com $50 \mathrm{~kg} / \mathrm{ha}$ de nitrogênio $(\mathrm{N})$ na forma de sulfato de amônio. $\mathrm{O}$ corte de uniformização foi realizado com auxílio de uma roçadeira costal e o material cortado foi mantido na área experimental.

A temperatura do ar média, durante o período experimental, variou de $22,5^{\circ} \mathrm{C}$ durante a parte da manhã (7h) a $30,5^{\circ} \mathrm{C}$ durante a tarde (14h). A umidade relativa do ar oscilou entre $92 \%$ pela manhã e $60 \%$ à tarde, nos mesmos horários. A precipitação pluvial total durante o período experimental foi de 118,6mm (Figura 1).

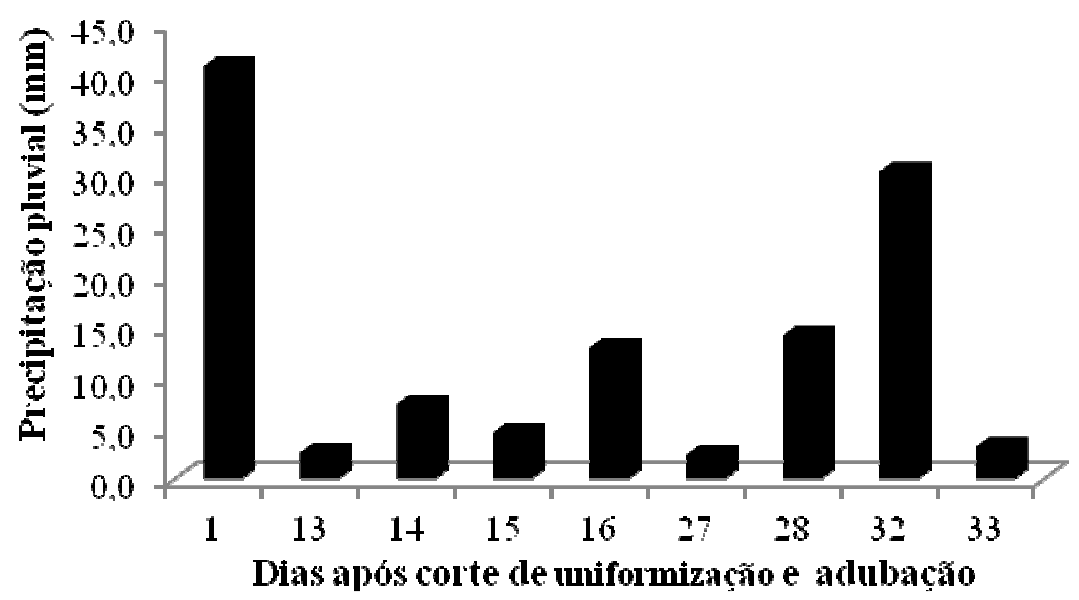

Figura 1. Precipitação pluvial em função dos dias de experimento

Foi utilizado um delineamento experimental de blocos completos ao acaso, com quatro tratamentos e cinco repetições. Os tratamentos compreenderam as alturas de corte do capim-buffel, sendo 30; 40; 50 e $60 \mathrm{~cm}$. As alturas de corte foram pré-determinadas com base no conhecimento do ciclo da espécie, através de pesquisas desenvolvidas anteriormente na região. Avaliou-se a altura comprimida, pelo método da régua e transparência. $\mathrm{O}$ capim após atingir $60 \mathrm{~cm}$ de altura comprimida paralisou seu crescimento, pelo fato de ter atingido o estádio fenológico de floração, de modo que essa foi a maior altura avaliada. As unidades experimentais apresentavam $4 \times 2 \mathrm{~m}$, totalizando $8 \mathrm{~m}^{2}$ cada. 
Foram realizadas quatro colheitas do capim à medida que atingia a altura determinada de cada tratamento, com 29; 36; 38 e 41 dias após o corte de uniformização a $10 \mathrm{~cm}$ do solo, para as alturas $30 ; 40 ; 50$ e $60 \mathrm{~cm}$, respectivamente.

Para avaliação da produtividade total de forragem, todo $\mathrm{o}$ material de cada unidade experimental, ao atingir o ponto de colheita, foi cortado a uma altura de $10 \mathrm{~cm}$ do solo e, em seguida, pesado para estimar a produtividade de matéria natural (PMN), em kg/ha. Uma parte da amostra de forragem foi destinada à determinação da matéria seca (MS), segundo Silva \& Queiroz (2002). A produção em matéria seca foi estimada pelo produto entre a PMN e o teor de MS, sendo, posteriormente, convertida em produção de matéria seca por hectare.

Para a caracterização dos constituintes colmo, lâmina foliar e relação lâmina/colmo, foi coletada uma amostra de cada unidade experimental, aleatoriamente de cada tratamento. Para coleta desta amostra foi utilizado um quadrado de área conhecida $0,5 \times 0,5 \mathrm{~m}$. Após colhida, a mesma foi homogeneizada e, posteriormente, retirada uma alíquota de aproximadamente $200 \mathrm{~g}$. Em seguida, foi realizada a separação em lâmina e colmo. O material foi armazenado em sacos identificados, pesados e acondicionados em estufa de ventilação forçada, durante 72 horas, a temperatura de $65^{\circ} \mathrm{C}$, até atingir peso constante, para se estabelecer a proporção com base na matéria seca. A partir da massa seca de lâminas foliares e colmos, estimou-se a relação lâmina/colmo.

Amostras de aproximadamente $2 \mathrm{~kg}$ de cada tratamento com cinco repetições foram expostas ao ambiente para a desidratação até atingir o ponto de feno, em torno de $15 \%$ de umidade. O tempo para o material atingir o ponto de feno foi de 32 horas. O material foi revolvido a cada 2 horas durante o dia com o intuito de uniformizar e acelerar o processo de desidratação. Para quantificação das perdas durante a desidratação o material foi coberto utilizando-se tela com malha $3 \times 3 \mathrm{~mm}$ para evitar a perda pela ação do vento e para que todo o material ficasse exposto ao sol. Após atingir o ponto de feno, o material foi pesado novamente para determinação dos cálculos das perdas.

Posteriormente, o material foi enfardado com auxílio de uma enfardadeira de madeira com dimensões de $25 \times 40$ x $40 \mathrm{~cm}$, de altura, comprimento e largura, respectivamente. Após a confecção dos fardos, os mesmos foram armazenados em local arejado, utilizando-se estrados de madeira para evitar contanto com o chão, do mesmo modo afastados das paredes do galpão. Após 60 dias de armazenamento, os fardos foram pesados para posterior cálculo das perdas durante o armazenamento.

A recuperação da matéria seca na desidratação (RMS Desidratação) foi calculada através da equação:

RMS Desidratação (\%) = MFad*MSad / MFc*MSc * 100, em que:

MFad = massa de forragem após a desidratação $(\mathrm{kg})$;

MSad = teor de matéria seca após a desidratação (\%);

$\mathrm{MFc}=$ massa de forragem no momento do corte $(\mathrm{kg})$;

$\mathrm{MSc}=$ teor de matéria seca no momento do corte $(\%)$; 
A recuperação da matéria seca final (RMS Final) foi calculada através da equação:

RMS Final $(\%)=$ MFaa*MSaa $/ \mathrm{MFc}^{*} \mathrm{MSc} * 100$, onde:

MFaa = massa de forragem após o armazenamento $(\mathrm{kg})$;

$\mathrm{MSaa}=$ teor de matéria seca após o armazenamento (\%);

$\mathrm{MFc}=$ massa de forragem no momento do corte $(\mathrm{kg})$;

$\mathrm{MSc}=$ teor de matéria seca no momento do corte $(\%)$;

Para determinação da composição química coletou-se aproximadamente $300 \mathrm{~g}$ de feno após o período de armazenamento, visando-se obter a composição do feno após todas as etapas do processo de fenação, o qual seria utilizado na alimentação animal. As amostras foram pré-secas em estufa de ventilação forçada a $60^{\circ} \mathrm{C}$, até atingir peso constante. Posteriormente, as amostras foram moídas em moinho de facas com peneira de $1 \mathrm{~mm}$ e acondicionadas em frascos de plástico. A partir destas realizaram-se as determinações de MS, proteína bruta $(\mathrm{PB})$, matéria mineral (MM) e extrato etéreo (EE) segundo metodologias descritas por Silva \& Queiroz (2002). O teor de fibra em detergente neutro (FDN) foi avaliado utilizando as composições de detergente recomendada por Mertens (2002), utilizando o analisador de fibra (Ankom 220). As análises laboratoriais foram realizadas no laboratório de Análise e Avaliação de Alimentos do Centro de Ciências Agrárias (CCA) da Universidade Federal da Paraíba (UFPB). Os dados obtidos foram submetidos à análise de variância e regressão. $\mathrm{O}$ efeito das alturas de corte foi avaliado por meio de análise de regressão, tomando-se como critério para escolha dos modelos, os valores dos coeficientes de determinação e a significância dos parâmetros da regressão, testados pelo teste $\mathrm{t}$, ao nível de $5 \%$ de significância, utilizando-se o
Sistema de Análises Estatísticas e Genéticas (UFV, 2007).

\section{RESULTADOS E DISCUSSÃO}

Os valores de produção de matéria seca e produção de matéria verde aumentaram linearmente $(\mathrm{P}<0,05)$ em função da altura de colheita (Figura 2a e 2b), alcançando PMS de $7.206,78 \mathrm{~kg} / \mathrm{ha}$ e PMV de $35832,00 \mathrm{~kg} / \mathrm{ha}$ quando colhido a $60 \mathrm{~cm}$ de altura (Figura 1a e $1 b)$. Vale ressaltar que essa produção foi alcançada com uma precipitação total de $118,6 \mathrm{~mm}$. A maior produção de matéria verde e seca com o aumento da altura de colheita pode ser explicada pelo fato de quanto maior a altura de colheita maior é o tempo para a espécie acumular biomassa. Edvan et al. (2011), trabalhando com intensidade e frequência de desfolhação do capim-buffel, observaram valores de PMN e PMS do capim-buffel inferiores ao presente trabalho, tendo em vista que a altura de resíduo utilizada foi diferente, $20 \mathrm{~cm}$, e a finalidade era simulação de pastejo.

Em pastagem de capim-buffel, assim como em outras gramíneas, a altura de corte é importante para se realizar um manejo correto, pois proporciona um melhor desempenho da forrageira, além de ser uma forma prática de manejar o pasto.

O tempo gasto para atingir a maior PMS, $7.206,78 \mathrm{~kg} / \mathrm{ha}$, foi de 41 dias. Dantas 
Neto et al. (2000) relataram valor de aproximadamente $5.000 \mathrm{~kg} / \mathrm{ha}$, com 80 dias após a emergência e sob lâmina de irrigação de $373 \mathrm{~mm}$. Entretanto, a determinação do tempo em dias pode variar de acordo com a disponibilidade de recursos edafoclimáticos como disponibilidade de água, temperatura e radiação solar, além de fatores relacionados à fertilidade de solo, por isso foi feita a proposta das alturas de corte nesta pesquisa.

Observou-se efeito de altura de colheita $(\mathrm{P}<0,05)$ para os percentuais de lâmina e colmo na MS (Figura 3a e 3b), com comportamento linear negativo $\mathrm{e}$ positivo, respectivamente. Esse comportamento é esperado, devido ao contínuo aumento no rendimento de matéria seca está associado à crescente proporção de colmo na biomassa do relvado, pois, com o avanço do desenvolvimento da forrageira, a proporção de folhas diminui progressivamente, com redução do conteúdo celular e do valor nutritivo da planta (VASCONCELOS et al., 2009).
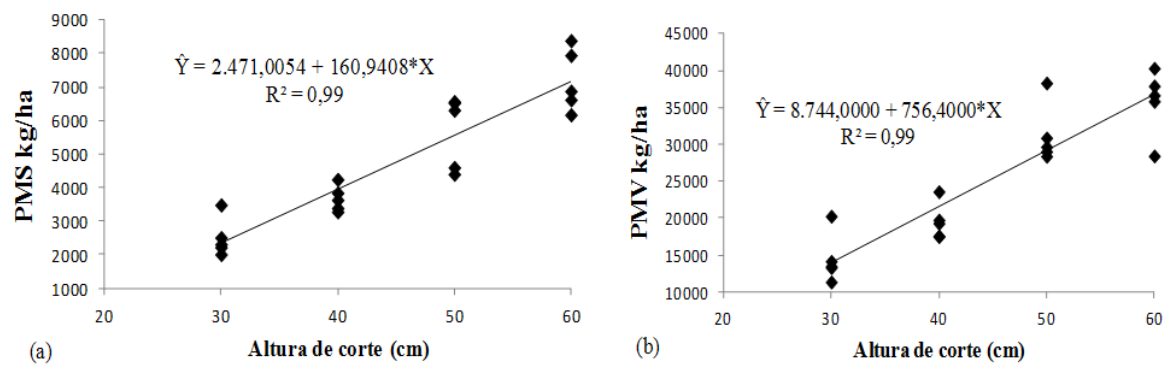

Figura 2. Produção de matéria seca (PMS) (a) e produção de matéria verde (PMV) (b) de capim-buffel colhido em diferentes alturas
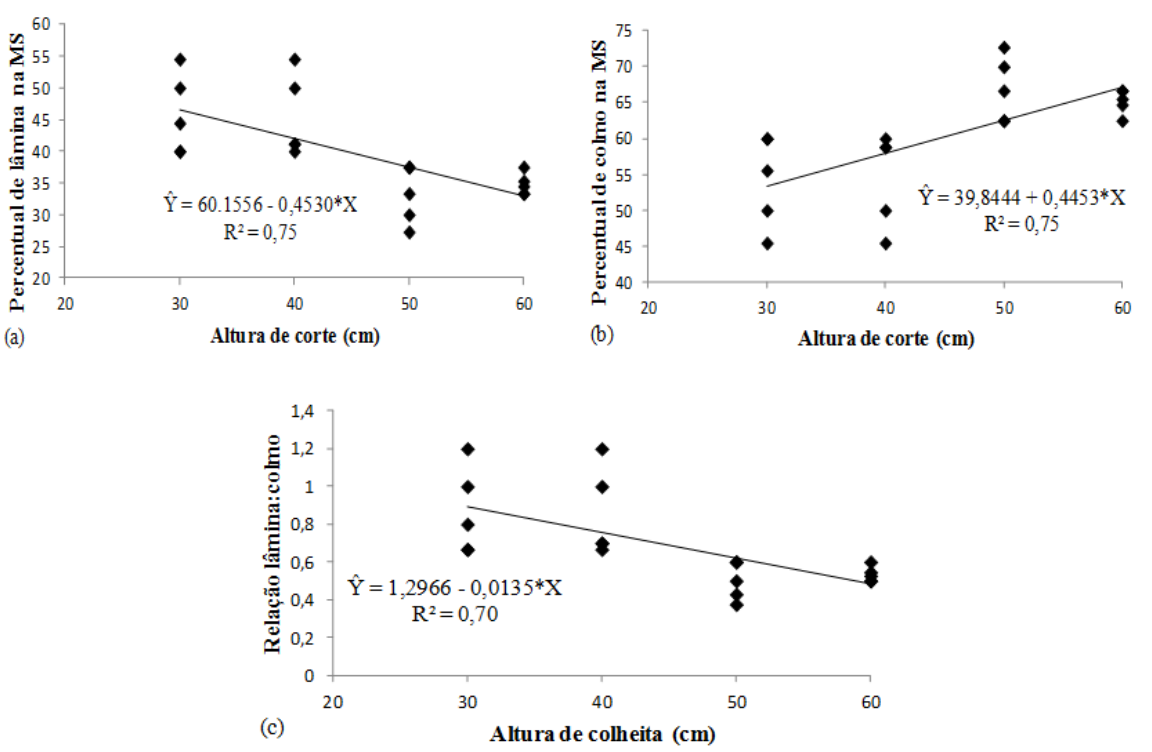

Figura 3. Percentual de lâmina (a) e colmo (b) na matéria seca e relação lâmina:colmo (c) do capim-buffel colhido em diferentes alturas 
Os valores da relação lâmina:colmo diminuíram linearmente $(\mathrm{P}<0,05)$ em função da altura de colheita (Figura $3 \mathrm{c}$ ), com resultado superior para a altura de colheita de $30 \mathrm{~cm}$, com relação lâmina:colmo de 0,87 . Este comportamento foi observado devido a planta nesta altura de colheita apresentar maior percentual de folhas e menor percentual de colmo (Figura 3a e 3b). Nesta altura de colheita a planta encontra-se em pleno desenvolvimento, deste modo tem-se uma priorização para o aparecimento e alongamento de folhas com objetivo de elevar sua capacidade fotossintética e, assim, acelerar seu crescimento e recuperar o estresse sofrido com o corte ou pastejo. A relação lâmina:colmo é uma variável de grande valia para o valor nutritivo e para o processo de desidratação do feno, uma vez que uma maior participação de folhas no material resulta em melhoria na composição química, além de favorecer o processo de desidratação.

Os valores de produção observados no presente trabalho ressaltam a capacidade de produção de forragem do capim-buffel em ambientes semiáridos para fins de conservação com o objetivo de suplementação volumosa no período seco.

A relação entre altura e produção é bastante conhecida, apresentando sempre aumento em função da idade ou da altura de corte do capim. Entretanto, a gramínea apresenta diferentes características em cada estádio de desenvolvimento e estas podem influenciar positiva ou negativamente $o$ processo de conservação da forragem adotado, como observado por Santos et al. (2011). Dessa forma, a recomendação do ponto de colheita para a fenação deve considerar, além da produtividade, características como valor nutricional e perdas no método de conservação. Em condições semiáridas o número de dias para atingir a altura de corte deve ser monitorado e pode influenciar na sua escolha, devido à possibilidade de mais cortes em alturas intermediárias.

Não houve efeito $(\mathrm{P}>0,05)$ de altura de colheita para os teores de MS (Tabela 1). Os valores médios de MS dos fenos situaram-se entre 82,44 e $84,48 \%$, dentro da faixa de umidade recomendada na qual a deterioração no armazenamento é mínima, que é de até $20 \%$. Este teor de umidade é muito importante, pois evita perdas durante o armazenamento. Segundo Reis et al. (2001), fenos armazenados com alto conteúdo de água apresentam elevadas perdas de MS, relacionadas com a continuação da respiração celular e ao desenvolvimento de bactérias, fungos e leveduras.

$\mathrm{O}$ teor de $\mathrm{PB}$ apresentou diminuição numérica com o aumento da altura de corte, apesar de não ter existido ajuste de modelos (Tabela 1), em decorrência do aumento do conteúdo de componentes fibrosos, corroborando com trabalho realizado Dantas Neto et al. (2000), no qual o teor de PB decresceu linearmente para o capimbuffel com o aumento da idade da planta, passando de $12,40 \%$ com cortes realizados aos 35 dias para $6,0 \%$ quando cortado aos 110 dias. Além disso, o aumento na PMS nas alturas de 50 e $60 \mathrm{~cm}$ pode explicar a diminuição no teor de PB através do efeito de diluição desse constituinte. Avaliando cinco genótipos de capim-buffel nas condições semiáridas do México, García-Dessommes et al. (2003) observaram valores de PB inferiores aos do presente trabalho, variando entre 7,5 e $9,2 \%$. A superioridade observada no presente trabalho pode ter sido devido à adubação nitrogenada. 
Rev. Bras. Saúde Prod. Anim., Salvador, v.14, n.3, p.437-447 jul./set., 2013 http://www.rbspa.ufba.br ISSN 15199940

Tabela 1. Valores médios da matéria seca (MS), matéria orgânica (MO), matéria mineral (MM), proteína bruta (PB) e extrato etéreo (EE) do feno de capimbuffel colhido em diferentes alturas

\begin{tabular}{lcccccc}
\hline \multirow{2}{*}{ Variáveis } & \multicolumn{4}{c}{ Altura de corte $(\mathrm{cm})$} & \multirow{2}{*}{ Média } & \multirow{2}{*}{ CV $(\%)$} \\
\cline { 2 - 4 } & 30 & 40 & 50 & 60 & & \\
\hline MS (\%) & 83,29 & 84,48 & 82,44 & 83,47 & 83,42 & 2,03 \\
MO (\%MS) & 86,91 & 88,85 & 88,07 & 88,14 & 87,99 & 1,06 \\
MM (\%MS) & 13,09 & 11,15 & 11,93 & 11,86 & 12,01 & 7,77 \\
PB (\%MS) & 16,11 & 18,07 & 12,95 & 12,25 & 14,85 & 7,12 \\
FDN (\%MS) & 74,34 & 71,82 & 75,19 & 77,08 & 74,61 & 6,38 \\
EE (\%MS) & 1,07 & 1,68 & 1,26 & 2,52 & 1,63 & 30,87 \\
\hline
\end{tabular}

$\mathrm{CV}=$ coeficiente de variação.

O teor de FDN, apesar de não ter sido observado ajuste de modelos lineares, observou-se um aumento à medida que se elevaram as alturas de colheita, com exceção para a o feno do capim-buffel colhido a $40 \mathrm{~cm}$ de altura, a partir desta altura o feno teve seu percentual de FDN aumentado até atingir 77,08 \%, quando colhido aos $60 \mathrm{~cm}$ de altura. Nelson \& Moser (1994) afirmaram que, com o aumento da idade, as gramíneas tropicais apresentam um processo acelerado de diferenciação morfológica, caracterizado por aumento dos tecidos de sustentação presentes na região do caule e redução nos tecidos relacionados ao conteúdo celular, como as folhas. Essa redução na relação lâmina/colmo é responsável pelo aumento nos teores de FDN e pela diminuição de nutrientes como a PB.

As perdas envolvidas no processo de fenação, bem como no armazenamento de fenos, são variáveis pouco avaliadas em trabalhos de pesquisa, apesar da extrema relevância. Vários tipos de perdas podem ocorrer no recolhimento do feno, além daquelas consideradas inevitáveis, como respiração celular, fermentação, lixiviação, decomposição de compostos nitrogenados e oxidação de vitaminas (REIS et al., 2001).
$\mathrm{Na}$ Figura 4, observa-se que a RMS desidratação diminuiu $(\mathrm{P}<0,05) \quad \mathrm{em}$ função das alturas de colheita, apresentando comportamento linear, sendo a menor média observada para o capim colhido a $60 \mathrm{~cm}$ (76,58\%). O aumento das perdas em função da idade de rebrotação pode ter sido ocasionado pelas modificações estruturais da planta, como a diminuição da relação lâmina:colmo (Figura 3c), uma vez que o colmo apresenta menor velocidade de desidratação em relação às folhas, permitindo a continuidade das atividades das células das plantas e de microrganismos por um período mais elevado.

Com relação à RMS final (Tabela 2), embora tenham sido observadas perdas variando de 15 a $37 \%$, esses valores estão próximos com os descritos por Rees (1982), que observou perdas de 18 a $30 \%$ entre todas as fases do processo de fenação, sendo maior parte desta perda resultante da respiração celular durante a desidratação. Ressalta-se também que no Cariri Paraibano, no período chuvoso, concentrado nos períodos mais frios do ano, a umidade relativa do ar é elevada, dificultando a desidratação do material, e que pode ter contribuído para os valores elevados de perdas. 


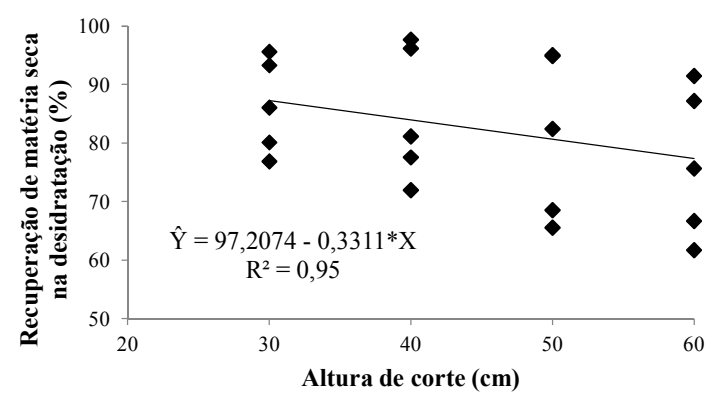

Figura 4.Recuperação de matéria seca na desidratação (\%) de feno de capim-buffel colhido em diferentes alturas de corte

Tabela 2. Valores médios da matéria seca da planta (MS Planta), matéria seca do feno (MS Feno), matéria seca do fardo após armazenamento (MS Fardo), e recuperação de matéria seca de todo o processo de fenação (RMS Final) do capim-buffel colhido em diferentes alturas

\begin{tabular}{lcccccc}
\hline \multirow{2}{*}{ Variáveis } & \multicolumn{4}{c}{ Altura da planta $(\mathrm{cm})$} & \multirow{2}{*}{ Média } & \multirow{2}{*}{ CV (\%) } \\
\cline { 2 - 5 } & 30 & 40 & 50 & 60 & & 11,31 \\
MSP(\%) & 17,31 & 18,96 & 18,23 & 20,17 & 18,67 & 17,93 \\
MS Feno (\%) & 71,82 & 79,09 & 71,97 & 72,82 & 73,93 & 7,69 \\
MS Fardo (\%) & 83,29 & 84,48 & 82,44 & 83,47 & 83,42 & 2,03 \\
RMS Final (\%) & 85,26 & 68,94 & 77,73 & 72,16 & 76,02 & 13,00 \\
\hline
\end{tabular}

$\overline{\mathrm{CV}}=$ coeficiente de variação.

As dificuldades na desidratação decorrente das alterações na composição morfológica das plantas podem influenciar diretamente as perdas no armazenamento, devido ao desenvolvimento de mofos e leveduras favorecido pelas condições de umidade e manutenção da atividade respiratória, principalmente pelo componente colmo. Além desses aspectos, as perdas que ocorrem durante as fases de desidratação e armazenamento têm influência acentuada sobre o valor nutritivo da forragem (REIS et al., 2001). No entanto, para a RMS final não foi possível ajustar um modelo que explicasse 0 seu comportamento, mesmo havendo efeito $(\mathrm{P}<0,05)$ das alturas de colheita, demonstrando que nas maiores alturas de colheita as perdas no processo de fenação são mais elevadas.

O monitoramento das perdas na fenação pode ser determinante nos custos de produção e de fundamental importância no planejamento alimentar de um rebanho, uma vez que são inevitáveis e de acordo com o manejo podem ser maiores que o esperado. Recomenda-se que os valores de perdas na desidratação e no armazenamento sejam considerados no cálculo da produtividade de feno de uma área, o que é pouco observado em propriedades rurais. 
Além disso, o manejo a ser adotado pode ser dependente da intensidade do sistema de produção e da disponibilidade de maquinário. De acordo com os resultados, o capimbuffel colhido nas maiores alturas, em torno de 50 a $60 \mathrm{~cm}$, apresenta valor nutricional e perdas na desidratação e no armazenamento semelhantes ao capim-buffel colhido nas menores alturas.

A ausência de variação nos constituintes bromatológicos e nas perdas de matéria seca final e as maiores produções de biomassa nas maiores alturas de colheita permite concluir que o capimbuffel seja colhido nas alturas de colheita que possibilite maior produção.

\section{REFERÊNCIAS}

AGUIAR, E.M.; LIMA, G.F.C.; SANTOS, M.V.F.; GUIM, A. MEDEIROS, H.R.; BORGES, A.Q. Rendimento e composição químicobromatológica de fenos de triturados de gramíneas tropicais. Revista Brasileira de Zootecnia, v.35, n.6, p.2226-2233, 2006.

DANTAS NETO, J.; SILVA, F.A.S.; FURTADO, D.A.; MATOS, J.A. Influência da precipitação e idade da planta na produção e composição química do capim-buffel. Pesquisa Agropecuária Brasileira, v.35, n.9, p.1867-1874, 2000.

EDVAN, R.L.; SANTOS, E.M.; SILVA, D.S.; ANDRADE, A.P.; COSTA, R.G.; VASCONCELOS, W.A. Características de produção do capimbuffel submetido a intensidades e freqüências de corte. Archivos de Zootecnia, v.60, n.232, p.1281-1289, 2011.
GARCÍA-DESSOMMES, G.J.; LOZANO, R.G.R.; FOROUGHBAKHCH, R.; RODRÍGUEZ, R.M.; DÍAZ, G.G. Ruminal digestion and chemical composition of new genotypes of buffel grass (Cenchrus ciliaris L.) Interciência, v.28, n.4, p.220-224, 2003.

MEDEIROS H.R.; DUBEUX JUNIOR, J.C.B. Efeitos da fertilização com nitrogênio sobre a produção e eficiência do uso da água em capim buffel. Revista Caatinga, v.21, n.3, p.13-15, 2008.

MERTENS, D.R. Gravimetric determination of amylase-treated neutral detergent fiber in feeds with refluxing in beaker or crucibles: collaborative study. Journal of AOAC International, v.85, p.1217-1240, 2002.

NELSON, C.J.; MOSER, L.E. Forage quality, evaluation, and utilization. Madison: Library of Congress, 1994. p.112-134.

REES, D.V.H. A discussion of the sources of dry matter loss during the process of haymaking. Journal of Agricultural Engineering Research, v.27, p.469-479, 1982.

REIS, R.A.; MOREIRA, A.L.; PEDREIRA, M.S. Técnicas para produção e conservação de fenos de forrageiras de alta qualidade. In: SIMPÓSIO SOBRE PRODUÇÃO E UTILIZAÇÃO DE FORRAGENS CONSERVADAS, 1., 2001, Maringá. Anais... Maringá: Universidade Estadual de Maringá, 2001. p.1-39.

UNIVERSIDADE FEDERAL DE VIÇOSA - UFV. SAEG. Sistema para Análises Estatísticas. Versão 9.1. Viçosa: Fundação Arthur Bernardes, 2007. 
SANTOS, E.M.; PEREIRA, O.G.; GARCIA, R.; FERREIRA, C.L.L.F.; OLIVEIRA, J.S.; SILVA, T.C.; ROSA, L.O. Microbial populations, fermentative profile and chemical composition of signalgrass silages at different regrowth ages. Revista Brasileira de Zootecnia, v.40, n.4, p.747-755, 2011.

SILVA, D.J.; QUEIROZ, A.C. Análises de alimentos: métodos químicos e biológicos. 3 ed. Viçosa, MG: UFV, 2002. 235p.
VASCONCELOS, W.A.; SANTOS, E.M.; ZANINE, A.M.; PINTO, T.F.; LIMA, W.C.; EDVAN, R.L.; PEREIRA, O.G. Valor nutritivo de silagens de capim-mombaça (Panicum maximum Jacq.) colhido em função de idades de rebrotação. Revista Brasileira de Saúde e Produção Animal [online], v.10, n.4, p.874-884, 2009.

Data de recebimento: $27 / 03 / 2013$

Data de aprovação: 17/09/2013 